\section{Research rewards are worth the effort for multitasking mothers}

SIR - The reasons women drop out of science are complex, and Timothy Roper and Larissa Conradt have hit on an important factor in their Correspondence 'Childcare not enough to make a science career family-friendly' (Nature 455, 1029; 2008).

However, I don't see encouraging more women into science as either pointless or unethical.

Careers in science can offer enormous rewards to women. Moving into an academic environment has provided great opportunities for me as a mother, owing to its flexibility. I am now measured largely on my productivity, and my ability to multitask - honed by motherhood - is an asset as I juggle research, administrative duties and teaching.

I have worked in the maledominated field of Antarctic research for the past 15 years, and I run a research programme looking at climatic warming impacts on the top predators, leopard seals. This work has been successful, thanks to my scientific team - which, incidentally, is mainly composed of women. As the mother of two children under the age of six, I suspect that a large part of my success has been due to the enduring support of my partner. I'm not going to pretend that it has been plain sailing, but I wouldn't have done it any differently.

Let's stop asking why there are so few women in science. Instead, let's turn the question round to ask how those who made it actually got there.

As scientists, we are skilled strategists, overseeing the conception of a new research initiative, then the project's gestation and its birth as a peer-reviewed article. These planning skills also sustain our lives outside the lab.

To those women embarking on the journey, I would say that it is not a road for everyone - but if, like me, you have a burning passion for your research, I would encourage you whole-heartedly to pursue it. It's a long journey, so pace yourself and plan — including your home life and time with your family in your plan. Sometimes you need to step back a little in order to move forwards.

Tracey L. Rogers Evolution and Ecology Research Centre, School of Biological, Earth and Environmental Sciences, University of New South Wales, Sydney 2052, Australia e-mail: tracey.rogers@unsw.edu.au

Readers are welcome to comment at http://tinyurl.com/56mavj

\section{What is nature, if it's more than just a place without people?}

SIR - Your Editorial 'Handle with care' (Nature 455, 263$264 ; 2008$ ) notes that many people define 'nature' as a place without people, and that this would suggest that nature is best protected by keeping humans far away. You question the value of this negative definition, arguing that "if nature is defined as a landscape uninfluenced by humankind, then there is no nature on the planet at all".

This may be true. However, if we define nature as including humankind, the concept becomes so all-encompassing as to be practically useless.

As an ecologist, I consider humans to be embedded in nature rather than separate from it. This relationship does not disappear in an urban environment. For example, the food you eat, the paper you read and the energy you consume are all products of multiple interacting organisms and ecosystem services. But if we adopt this inclusive definition, it becomes impossible to identify anything on the planet that is not a part of 'nature'. In this case, an atom bomb becomes as 'natural' as an anthill.
A dilemma therefore arises.

If nature is somewhere that humans are not, we lose sight of the fact that we are just another species intimately intertwined in the complex web of biological systems on this planet. However, if we place ourselves within a definition of nature, the definition then becomes essentially meaningless by extending to everything on Earth.

Your Editorial comments that “Nature doesn't have to end if we stop defining it by humankind's absence". The problem is that once we no longer define nature by our absence, the concept has no end.

Is there a better definition of nature?

Fern Wickson Centre for the Study of the Sciences and the Humanities, University of Bergen, PO Box 7805, 5020 Bergen, Norway e-mail: fern.wickson@svt.uib.no

\section{Progress being made on standards for use in data sharing}

SIR - In his Correspondence on data sharing ('Big data: opensource format needed to aid wiki collaboration' Nature 455, 461; 2008), Tin-Lap Lee points out "there is currently no de facto standard on pathway-data format, which severely limits data portability". Although this statement is correct, there are three particular standards in use - BioPAX (www.biopax.org), CellML (www.cellml.org) and the Systems Biology Markup

Language (www.sbml.org) - that all serve this purpose.

These standards can provide annotations based on appropriate ontologies. In other words,

they provide an indexing system that gives unambiguous representations of the entities that they describe, thereby avoiding the problem of synonyms (see M. J. Herrgård et al. Nature Biotechnol. 26, 1155-1160; 2008).

MIRIAM is a community recommendation for minimal information to be reported about models and can be used with any of the three standards (N. Le Novère et al. Nature Biotechnol. 23, 1509-1515; 2005).

I would strongly recommend that everyone with an interest in sharing models should do so using one or more of these formats.

Douglas Bruce Kell Manchester Centre for Integrative Systems Biology, School of Chemistry, and Manchester Interdisciplinary Biocentre, University of Manchester, 131 Princess Street, Manchester M17DN, UK e-mail:dbk@manchester.ac.uk

\section{One-year practical course proves a launch pad for PhDs}

SIR — In response to Cristina Banks-Leite's comments in Correspondence ('More ground work needed to prepare students for PhDs' Nature 455, 285; 2008)

- I couldn't agree more.

I secured a PhD scholarship straight from being an undergraduate. In retrospect, I believe that both I and my PhD supervisor would have benefited enormously if I had gone through the process of acquiring an MSc, and as a side effect been at least a year older, if not wiser.

A few years and many more mistakes down the line, I now teach on a programme whose main mission is to prepare students to be researchers in human and applied physiology. Practicals far outweigh the lecture time and intake is severely limited (despite the economics), so everyone's hands can get dirty. Experiments, not demonstrations, are the order of the day.

Furthermore, research projects without at least the intention of publication are dirty words!

Sitting on the other side of the selection-panel desk, I see a succession of bright, talented and enthusiastic souls attempting to explain why they - holding excellent grades from a course with lecture theatres full to the brim, but having never touched 